ARTIGO

\title{
UMA BASE PARA A SEMIFORMAÇÃO SOCIALIZADA: A VULGARIZAÇÃO DA CRÍTICA COMO ESTRATÉGIA DE PRODUÇÃO DO CONSENSO
}

\author{
PRISCILA MONTEIRO CHAVES ${ }^{2}$ \\ ORCID: http://orcid.org/0000-0002-3986-6157
}

\begin{abstract}
RESUMO: Considerando o empreendimento que vem ocorrendo para a implementação da Base Nacional Comum Curricular, neste artigo é proposta uma análise da sua última versão com foco específico no que é normatizado para o ensino de Língua Portuguesa no Ensino Fundamental, estabelecendo relações, em um segundo plano, com a área das linguagens nessa mesma etapa da educação. A perspectiva metodológica utilizada é a análise crítica discursiva, ancorada nas relações dialéticas entre linguagem e prática social, partindo do pressuposto que, no âmbito do discurso, é possível compreender as coerções políticas e sociais. Infere-se que a política em questão opera na inserção das ideias de regeneração aparente da cultura democrática, de estimulo não à cultura radicalmente participativa, mas da socialização da pseudoparticipação, como mais uma força no progresso dos interesses das frações da burguesia e se vale de um arsenal teórico-discursivo crítico e engajado como mais uma estratégia de produção de consenso entre os professores.
\end{abstract}

Palavras-chave: BNCC, Língua Portuguesa, semiformação socializada, linguagem.

\section{A BASIS FOR SOCIALIZED SEMIFORMATION: THE VULGARIZATION OF CRITICISM AS A CONSENSUS-PRODUCING STRATEGY}

\begin{abstract}
Considering the undertaking that has been underway for implementing the National Common Curricular Base (Base Nacional Comum Curricular BNCC), this article proposes an analysis of its latest version with a specific focus on what is standardized for the teaching of Portuguese in Elementary Education, establishing relationships, in the background, with the area of languages at the same stage of schooling. The methodological perspective used is critical discourse analysis (CDA), anchored in the dialectical relations between language and social practice, based on the assumption that, within the scope of discourse, it is possible to understand political and social constraints. It is inferred that the policy in question operates by inserting the ideas of apparent regeneration of the democratic culture, by stimulating the socialization of pseudoparticipation rather than radically participative culture, as yet another force in the
\end{abstract}

\footnotetext{
${ }^{1}$ Uma versão inicial desta discussão foi apresentada na mesa de encerramento do VI Congresso Regional de Docência e Educação Básica - Base Nacional Comum Curricular, realizado nos dias 27 e 28 de junho de 2019, na Universidade do Oeste de Santa Catarina.

${ }^{2}$ Universidade Federal do Espírito Santo. Vitória, Espírito Santo (ES), Brasil. <priscila.chaves.ufes@gmail.com>

Educação em Revista|Belo Horizonte|v.37|e228059|2021
} 
progress of fractions of bourgeois interests, and avails itself of a critical and engaged theoretical-discursive arsenal as yet another consensus-producing strategy among teachers.

Keywords: BNCC, Portuguese language, socialized semiformation, language.

\section{UNA BASE PARA LA SEMIFORMACIÓN SOCIALIZADA: LA VULGARIZACIÓN DE LA CRÍTICA COMO ESTRATEGIA EN LA PRODUCCIÓN DEL CONSENSO}

RESÚMEN: Teniendo en cuenta el compromiso que se ha estado llevando a cabo para la implementación de la Base Nacional Comum Curricular, este artículo propone un análisis de su última versión con un enfoque específico en lo que está estandarizado para la enseñanza del portugués en la escuela primaria, estableciendo relaciones, en el fondo, centrándose en el área del lenguaje en esta misma etapa de la educación. La metodología utilizada es el análisis crítico discursivo, anclado en las relaciones dialécticas entre el lenguaje y la práctica social, suponiendo que en el contexto del discurso es posible comprender los determinantes del lenguaje sociopolítico. Se concluye que la política en cuestión opera en la inserción de las ideas de regeneración aparente de la cultura democrática, en la socialización de la pseudoparticipación, como una más fuerza en el progreso de los intereses de la burguesía; y se basa en un arsenal teórico discursivo crítico y comprometido como una estrategia de producción del consenso entre los docentes.

Palabras clave: BNCC, Lengua portuguesa, semiformación socializada, lenguajes. 


\section{BREVE PANORAMA INTRODUTÓRIO}

"Onde estão os pressupostos da revolução? Na transformação das
opiniões ou na transformação das relaçôes externas?"
(BENJAMIN, 1994, p. 33)

Passados três anos de sua aprovação, a Base Nacional Comum Curricular se instala na alma da nossa atividade docente, seja na Educação Básica ou no Ensino Superior, nos cursos de licenciatura (BRASIL. CNE, 2019), pois trata-se de “[...] um documento de caráter normativo que define o conjunto orgânico $e$ progressivo de aprendizagens essenciais que todos os alunos devem desenvolver ao longo das etapas e modalidades da Educação Básica" (BRASIL, 2017, p. 7). Por seu caráter mandatório, a implementação permanece acontecendo até mesmo em tempos de crise sanitária e isolamento social, com as atividades de ensino remoto (PEREIRA et al, 2020) e com a progressiva instituição do ensino híbrido que vem ocorrendo nas escolas e se disseminando como projeto de educação para a classe trabalhadora (CHAVES; FLORES; EVANGELISTA, 2020).

Fazendo menção à legislação um tanto mais recente, já era prevista na Constituição Federal de 1988 (BRASIL, 1988) uma política pública que definisse a ação de elaboração dos currículos da Educação Básica. Essa necessidade foi ratificada onze anos depois pela Lei de Diretrizes e Bases da Educação Nacional no 9.394/96 (BRASIL, 1996). Nos dez primeiros anos deste século, foram publicados documentos orientadores para a Educação Infantil, Ensino Médio e para o então instituído Ensino Fundamental de Nove Anos (BRASIL, 2009). Posteriormente, foram publicadas as Diretrizes Curriculares Nacionais que descreveram direitos de aprendizagem para diferentes segmentos e modalidades do ensino e sinalizaram a necessidade de uma base nacional. Em 2014, a Lei 13.005 instituiu o Plano Nacional de Educação - PNE 2014-2024 (BRASIL, 2014), o qual, em sua redação, não veta o investimento de recursos públicos para educação privada, chancela o prolongamento de programas de avaliação estandardizada com estreita harmonização quanto às avaliações internacionais e suas finalidades e ratifica a relevância de uma base. Isso deixa evidente aos cenários nacional e internacional que as preocupações com as políticas curriculares brasileiras duram, ao menos, meio século. Além disso, mostra que são motivadas, fundamentalmente, pelas negociações das frações da burguesia nacional brasileira que respondem à ostensiva indicação da necessidade de reformas no plano educacional por Organismos Multilaterais, no que compete à formação docente, avaliações e instituição de um currículo único.

No contexto brasileiro, a elaboração e a implementação da BNCC vêm contando com o forte apoio de associações de monopólios empresariais fazendo as vezes do Estado. Como bem notam Neves e Piccinini (2018), esse não é um fenômeno hodierno ou que se restrinja à BNCC. A constituição de '[...] 'esferas de influência' é típica, por exemplo, da organização Todos Pela Educação, expoente ideológico do empresariado para a educação pública, um dos apoiadores do MPB, que há tempos se articula com a burocracia estatal através de figuras de distintos campos ideológicos” (2018, p. 195).

Com efeito, a BNCC se tornou pauta de discussão na esfera pública quando da divulgação da sua primeira versão, em setembro de 2015, ocasião em que a liderança do Partido dos Trabalhadores sofria intensa crise política, em estreito vínculo e decorrência das crises estruturais do capital e da necessidade de manutenção dos padrões de acumulação. ${ }^{3}$ No ano seguinte, temos a divulgação da

\footnotetext{
3 Tratando a temática de modo mais recente e mais significativo para o que se constata nas políticas educacionais hoje, notemos, de acordo com Vieira e Lamosa (2017), que as reformas do Estado, a partir da década de 90, no Brasil e no mundo, respondem à reestruturação do capital. "Para retomar os níveis de rentabilidades das empresas transnacionais e do capital financeiro, afetados pela crise do petróleo na década de 1970, as frações do capital, tanto dos países do centro do capitalismo quanto das economias dependentes, articularam uma saída para a crise” (p. 4). Nesse cenário, a ofensiva do capital não ocorreu somente contra os trabalhadores em suas circunstâncias imediatas. A promoção das estratégias que compreenderam a redefinição do papel do Estado envolveu as questões atinentes à educação da classe trabalhadora, que precisaria responder às necessidades postas por tal reestruturação. O que, impreterivelmente, envolve as políticas curriculares, de avaliação e de Educação em Revista|Belo Horizonte|v.37|e228059|2021
} 
segunda versão do documento, ainda sob o governo de Dilma Rousseff. Tanto uma quanto outra proposta de Base diziam determinar aprendizagens fundamentais em todas as etapas da Educação Básica. Em decorrência do golpe jurídico-midiático-parlamentar (FONTES, 2017), a terceira versão e a versão final da BNCC foram definidas e publicadas sob o governo do Partido do Movimento Democrático Brasileiro (PMDB) e lograram ainda mais evidência as competências (cognitivas e socioemocionais) e habilidades a serem desenvolvidas (especialmente essas).

A alternância de lideranças no aparelho de Estado modificou o arranjo de alguns agentes políticos coadjuvantes na constituição da Base, mas não seu conteúdo estrutural e nem a participação do empresariado na sua proposição, elaboração, redação e aceleração de movimentos políticos que criavam as condições para sua materialização e plena implementação. Algumas representações de pesquisadores das universidades envolvidas foram dispensadas do processo e o empresariado obteve ainda mais proeminência, principalmente pela atuação da Fundação Lemann ${ }^{4}$, vinculada ao extenso Cenpec, dos Institutos Natura, Ayrton Senna, Unibanco, Fernando Henrique Cardoso, da Fundação SM e Insper e outros que compõem o Movimento pela Base. Movimento esse que, desde sua origem, apresentou-se como apartidário e se valia da participação de membros dos dois maiores partidos brasileiros (PT e PSDB) pra forjar esse caráter. Inclusive, integrantes enfatizaram essa característica nos momentos mais tensos do processo para que a agenda não estacionasse apesar de qualquer conjuntura. A título de exemplo, no momento em que a polarização política partidária eclodiu, “[...] em março de 2016, três membros do Movimento escreveram um artigo apartidário para um grande diário paulista ${ }^{5}$, afirmando a necessidade de avançar para além das diferenças políticas e apoiar a BNCC em nome das 'crianças e jovens nas salas de aula"' (TARLAU; MOELLER, 2020, p. 579).

Por mais que ainda não detectemos hoje as estreitas afinidades entre as avaliações em larga escala e o que prescreve a BNCC, segundo Freitas (2018, s/p), ela compõe "[...] uma política educacional que propõe melhorar a educação brasileira através do seu atrelamento do ensino a avaliações censitárias (de todos os estudantes) em escala nacional (Prova Brasil e ANA, por exemplo), o que obriga os Estados a aplicar a BNCC" e vem motivando, nos currículos escolares, semelhança ainda maior. O autor complementa afirmando que, se assim ocorre, "[...] um Estado não pode criar, de fato, seu próprio currículo, pois seus alunos serão testados segundo avaliações nacionais feitas a partir da BNCC do MEC e não de um eventual currículo do Estado" (FREITAS, 2018, s/p).

Vimos presenciando como a disputa por posição e consenso na sociedade civil se vale, no seio do novo ativismo burguês, de redes formais e informais para ocupar o balcão de negócios e fazer com que as tratativas políticas pareçam puramente técnicas e científicas. Lembremos aqui do que disse Palácios, então Secretário de Educação Básica do Ministério da Educação (2015-2016), citado por Tarlau e Moeller (2020, p. 578), ao ser questionado sobre os modos como o Movimento pela Base angariou rapidamente apoio da população quanto à recepção positiva da BNCC: "A participação da Lemann foi muito importante. Especialmente na relação com os meios de comunicação. Em todas as situações de dificuldade, em momentos conturbados politicamente, ela foi fiadora desse movimento em setores sobre

formação desses educadores. Se 'em meados da década de 1990, verificou-se que o novo padrão de acumulação do capital e o novo padrão tecnológico de produção resultou no aumento da pobreza, do desemprego, e do subemprego e dos movimentos antiglobalização" (VIEIRA; LAMOSA, 2017, p.5), é também no campo educacional que esses desajustes serão parcamente resolvidos a curto e longo prazo.

${ }^{4}$ Ainda que outras instituições tenham sido chamadas a integrar o Movimento pela Base, não podemos perder de vista que sua criação se deu por iniciativa da Fundação Lemann, que sempre esteve à frente do processo e tinha a intenção de constituir um bloco de apoio hegemônico para a cadeia de sustentação de seu principal empreendimento no contexto da educação brasileira. Isso nos indica que os antagonismos entre o que propõe o documento e o que vislumbravam os professores e parte da comunidade científica que eram a favor da existência de uma base não seriam resolvidos com maior tempo de discussão, como reivindicam algumas apreciações. A Fundação Lemann delineou o processo também patrocinando pesquisas $\mathrm{e}$ realizando seminários educacionais fora do país, “[...] pagou as refeições durante as reuniões e comprou passagens aéreas, de forma que os funcionários do MEC, do Conselho Nacional dos Secretários de Educação (Consed) e da União Nacional dos Dirigentes Municipais de Educação (Undime) pudessem participar de eventos nacionais. [...] A Fundação Lemann estava sempre à mesa, já que, literalmente, pagava o almoço" (TARLAU; MOELLER, 2020, p. 575).

5 Disponível em: <https://www1.folha.uol.com.br/paywall/login.shtml?https://www1.folha.uol.com.br/opiniao/ 2016/05/1767087-os-estudantes-nao-podem-esperar.shtml>. Acesso em: 26 ago. 2019.

Educação em Revista|Belo Horizonte|v.37|e228059|2021 
os quais não tinha nenhuma influência". As autoras comentam que a Fundação Lemann orquestrou uma "[...] estratégia de mídia, em que representantes da fundação treinaram dezenas de jornalistas para cobrir questões educacionais, inclusive a BNCC, e apresentá-las de forma positiva. A fundação organizou eventos de alto nível que receberam grande cobertura da mídia” (2020, p. 578).

Fazer esse arrazoado é importante para mostrar que não faz sentido ler este escrito desencarnado da dinâmica material que produziu a política educacional em questão. Ele constitui uma peça a mais que se inscreve na compreensão do movimento real do todo, das leis gerais do objeto, para rastrear e compor, pela sua expressão, o conjunto das conexões íntimas, uma vez que a aura de inevitabilidade vai se tornando mais verossímil pelo jogo político, pela fala dos especialistas, pela produção de matérias, pela articulação com a mídia e pela força da lei. Assim, levando em conta o referido cenário, o objetivo do presente estudo é discutir em que medida a Base Nacional Comum Curricular brasileira, valendo-se das convicções teórico-práticas dos professores na área das linguagens, facilita a constituição de consenso generalizado e devolve aos docentes e aos filhos da classe trabalhadora uma normatização da semiformação socializada.

"A fecundidade do documento pede: análise", dizia Walter Benjamin (2013, p. 29). Para tanto, elegemos a área das linguagens no referido documento, no que compete ao Ensino Fundamental ${ }^{6}$ (com foco no ensino da Língua Portuguesa), para o desenvolvimento desta apreciação. Essa escolha foi motivada por dois principais aspectos: 1) a referida área compõe $50 \%{ }^{7}$ do volume de páginas destinadas no documento a essa etapa da Educação Básica (BRASIL, 2017) e 2) o ensino de Língua Portuguesa (sua maior parte) é um grande pilar das avaliações em larga escala, estando constantemente no fulcro das propostas e reformas educacionais pelo interesse que há em fazer desses resultados moeda de troca nas negociações internacionais. Em estreita afinidade com a perspectiva política e filosófica da qual é feito uso na apreciação, o percurso metodológico se valeu, de maneira mais global, de alguns preceitos da Análise Crítica Discursiva, difundida por Norman Fairclough (2001; 2012), que consiste em um estudo enraizado nas relações dialéticas entre linguagem e prática social. No que concerne às mesmas relações acrescidas de aspectos mais pormenorizados da interpretação do documento, as contribuições de José Luiz Fiorin (2000) foram juntamente consideradas.

Partindo do pressuposto de que no âmbito do discurso é possível compreender as coerções sócio-políticas determinantes da linguagem, a ACD apresenta uma proposta demarcadamente edificada em oposição aos discursos pautados pela sustentação do status quo das relações de exploração entre as classes sociais. Considerando que o discurso torna materializados e notáveis os aspectos ideológicos, as representações inexistem fora das diferentes circunstâncias da linguagem. Se assim o é, as distintas maneiras de compreender o mundo existem e se exteriorizam nas formações discursivas (FIORIN, 2000). A ACD fornece elementos para a formulação de propostas contra-hegemônicas ${ }^{8}$ na medida que problematiza as práticas discursivas que atuam na tentativa de adaptação massiva de uma classe subalternizada ao sistema produtivo vigente. Ou seja, é um instrumento teórico-metodológico, de base

\footnotetext{
${ }^{6} \mathrm{O}$ Ensino Fundamental foi elegido como parte da empiria a ser analisada uma vez que das 1.529 habilidades apresentadas pelo documento, 1.304 são atinentes a essa etapa da Educação Básica.

${ }^{7}$ Dentre as 402 páginas destinadas à normatização do Ensino Fundamental na BNCC, 201 páginas são dedicadas à área das linguagens, das quais, 125 tratam somente da LP nessa etapa.

${ }^{8}$ Conceito que expressa uma oposição à relação unilateral de dominação pautada estritamente por aspectos econômicos. Na acepção de Raymond Williams (1979, p. 113), a ideia de hegemonia trata de uma relação de subordinação em sua manifestação "[...] como consciência prática, como efeito de saturação de todo o processo de vida, [...] de toda a substância de identidade e relações vividas, a uma tal profundidade que as pressões e limites do que se pode ver, em última análise, como sistema econômico, político e cultural, nos parecem pressões e limites de simples experiência e bom senso". Williams reforça nesse conceito seu caráter dinâmico, processual, tratando-o como “[...] um complexo realizado de experiências, relações e atividades, com pressões e limites específicos e mutáveis", o que nos impede de entendê-lo como dominação unilateral, passiva, pura e simplesmente. Para o autor, até mesmo a dinamicidade com que ela se renova, se movimenta e responde à resistência é elemento para sua sustentação. Acepção que se assemelha ao que propôs Antonio Gramsci, ao se contrapor às noções que advêm do campo semântico da supremacia ou da preeminência, dando centralidade para o duplo movimento de direção e domínio. Desse modo, se ela possui esse caráter processual e somente existe nas relações sociais, implica, inevitavelmente, experiências contra-hegemônicas. Assim, ainda que dominante, a hegemonia não será absoluta.

Educação em Revista|Belo Horizonte|v.37|e228059|2021
} 
materialista-histórica ${ }^{9}$, para a investigação dessas formações discursivas que se estabelecem nas relações de poder, demonstrando também como "[...] o público é educado perante os documentos" (BENJAMIN, 2013 , p. 29) e como eles reforçam as estruturas sociopolíticas, fazendo-as perdurar (FAIRCLOUGH, 2001).

Justamente pelas relações filosóficas e políticas nas quais se esteia essa perspectiva teóricometodológica é que se tornou necessário apresentar esse introdutório histórico e a brevíssima manifestação da comunidade científica mais panorâmica a qual esta proposta se filia. Isto é, de um modo geral, a partir daquilo que já foi dito e publicado sobre a BNCC em uma perspectiva global, tornam-se também relevantes os diferentes estudos das partes, para que possam ser compreendidos tanto as determinações sociais sofridas pelo documento quanto os diferentes modos como o consenso vem sendo produzido com base nas estratégias em que o próprio documento se ampara.

É verdade que o currículo praticado nas escolas não pode ser reduzido à BNCC, do contrário, estariam sendo ignoradas as contradições da realidade material e a possibilidade de organização social dos sujeitos históricos. Entretanto, negar a sua força hegemônica nas deliberações dos caminhos da educação pública, além de ingênuo, seria negar a dinamicidade da língua e as propriedades de direção e domínio imanentes ao capital.

\section{ELEMENTOS DOCUMENTAIS PARA A COMPREENSÃO DA BNCC}

Além de um certo pragmatismo destituir cada vez mais a escola de suas funções essenciais, Carvalho (2017, p. 30) chama a atenção para o fato de que "[...] pensar a experiência escolar a partir de suas finalidades práticas e de sua suposta relevância econômica tem posto em risco a possibilidade de se atribuir à formação educacional um significado político e existencial". Se antes tal preocupação se justificava por uma adoção cega dos célebres métodos de aprendizagem, hoje, essa destituição é atualizada e se manifesta repaginada pela crítica insuficiente estabelecida às concepções que não respondem mais às necessidades dos tempos hodiernos. Isso se faz relevante uma vez que a leitura um pouco mais minuciosa da BNCC nos apresenta uma particular constância de alguns aspectos. Notemos e reflitamos sobre parte dos que seguem: 1) a relação estabelecida entre suas habilidades e competências e os diferentes objetos do conhecimento; 2) a escolha dos verbos que conferem sentido e normatizam as atividades em torno desses objetos; e 3) a adesão aparente ao arcabouço teórico-crítico nas diferentes áreas do conhecimento.

Sem ignorarmos que "[...] a inocência serve de capa ao documento" (BENJAMIN, 2013, p. 29), lembremos que a BNCC assegura que "[...] as habilidades não descrevem ações ou condutas esperadas do professor, nem induzem à opção por abordagens ou metodologias” (BRASIL, 2017, p. 30). Essas opções estariam "[...] no âmbito dos currículos e dos projetos pedagógicos, que, como já mencionado, devem ser adequados à realidade de cada sistema ou rede de ensino e a cada instituição escolar, considerando o contexto e as características dos seus alunos" (BRASIL, 2017, p. 30). Entretanto, a exaustão e o detalhamento com que as competências e habilidades são relacionadas a objetos do conhecimento, além de manifestarem, em alguma medida, contrassenso a essa informação, entram também em contradição com a ideia central do que seria uma base curricular ${ }^{10}$.

\footnotetext{
${ }^{9}$ Em Linguagem e Ideologia (2000), José Luiz Fiorin torna ainda mais evidente essa relação entre o lugar das determinações ideológicas e as formas de compressão da realidade. Segundo ele, “[...] as relações que, no nível da superfície, apresentam-se como relações entre indivíduos são, no nível de essência, uma relação entre classes sociais, uma que se apropria do valor produzido pelo trabalho não-pago e outra que vende sua força de trabalho e é espoliada. As relações igualitárias de troca existem apenas no nível fenomênico. Isso quer dizer que há uma troca de equivalentes, isto é, igualdade na troca. No entanto, ela ocorre apenas no nível da circulação. Isso significa que ela, ao mesmo tempo, é afirmada e negada. É afirmada no nível fenomênico e negada no nível profundo, em que não há equivalência, nem troca, mas simplesmente apropriação" (2000, p. 27).

${ }^{10}$ Segundo Macedo, quando da exposição do "[...] documento aprovado pelo CNE, o MEC mantém apenas a forma trocadilho do original e proclama que 'educação é a base'. O que esta frase nos diz sobre a ideia de educação com que o MEC trabalha? Que a base de que se está falando - nacional curricular comum - é o mesmo que (ou contempla) a educação que pretendemos dar às nossas crianças. Não fosse este um dos sentidos possíveis, o trocadilho não se aplicaria. A leitura mais benevolente diz-nos que a educação é a base para outras conquistas, seja para o país, seja para cada um de nós. Ainda que se Educação em Revista|Belo Horizonte|v.37|e228059|2021
} 
É no mínimo funesta a tentativa de distinção exposta pelo MEC e defendida no que enunciou Mendonça Filho à frente do Ministério da Educação naquele momento, quando garantiu que a BNCC seria "[...] o ponto ao qual se quer chegar em cada etapa da Educação Básica, enquanto os currículos traçam o caminho até lá" (MEC, 2017, p. 5). É possível dizer isso pela constatação de convênios, acordos e demais contratações de diferentes secretarias de educação municipal e instituições privadas ou consultorias por pagamento de autônomos para a reprodução - por vezes eufemisticamente nomeada transposição - da Base em currículos para as escolas públicas de Educação Básica.

Para além dessa constatação, os agentes envolvidos na proposição de um documento que se estrutura com foco nas habilidades e competências e conta com uma discriminação bastante minuciosa dos objetos do conhecimento a serem trabalhados não parecem se preocupar somente com "[...] o ponto ao qual se quer chegar" ", mas, inclusive e provavelmente, com a responsabilização dos professores e das instituições de ensino quando essas habilidades e competências não puderem ser corroboradas instrumentalmente nas avaliações em larga escala.

Como exemplo bastante ilustrativo do que foi afirmado, podem ser referenciadas algumas habilidades requeridas para o $3^{\circ}$ ano do Ensino Fundamental, nas quais constam: "(EF03LP01) Ler e escrever palavras com correspondências regulares contextuais entre grafemas e fonemas - c/qu; $\mathrm{g} / \mathrm{gu}$; r/rr; s/ss; o (e não u) e e (e não i) em sílaba átona em final de palavra - e com marcas de nasalidade (til, m, n)" (2017, p. 115). Ou, de modo ainda mais esmiuçado na mesma página do documento, "[...] (EF03LP03) Ler e escrever corretamente palavras com os dígrafos lh, nh, ch" (BRASIL, 2017, p. 115). E importante afirmar ainda que não se trata de manifestar oposição à relevância de tais aspectos linguísticoformais, assim como de outras especificidades do processo de apropriação do sistema de escrita alfabética. O que se questiona é o fato de um documento normativo, que se define como base, necessariamente dar proeminência a elementos tão pontuais e de fácil fiscalização quando recortados seus aspectos instrumentais.

Muito já se tem discutido acerca da redução do processo formativo do sujeito a uma perspectiva que atente às competências concentradas nas demandas do mercado de trabalho. Sob o discurso pautado pelo ideário da empregabilidade aliado à “[...] expansão do trabalho parcial, temporário, precário, subcontratado, terceirizado" (ANTUNES, 2006, p. 41), vem restando à educação principalmente à educação pública - a oferta para a classe trabalhadora do privilégio de ser servil (ANTUNES, 2018), de ter pragmaticamente suas competências cognitivas e socioemocionais desenvolvidas (CHAVES; EVANGELISTA, 2020), para que possam ser flexivelmente úteis ao processo produtivo de trabalho. ${ }^{12}$

tenha construído em torno deste segundo sentido uma certa aura positiva, há, nele, a assunção de que a educação precisa, pragmaticamente, ser útil para algo que virá. Assim, ela é marquetizada, um bem a ser trocado no mercado futuro” (2018, p. 28).

11 Manifestação já indicada por Palácios, quando do início das exposições públicas sobre a proposta preliminar, ao afirmar estreita relação entre a BNCC e as avaliações nacionais. "A Base Nacional Comum Curricular vai funcionar como uma cartilha para determinar o que todos os estudantes brasileiros têm direito e devem aprender durante o ensino público". Sendo assim, segundo ele, o documento seria tomado como "[...] um guia para suas aulas. Ela irá, ainda, reorganizar todo o sistema educacional, materiais didáticos, formação de professores, avaliações que terão a Base como referência" (PALÁCIOS, 2015, apud PERONI; CAETANO, 2015, p. 342, grifos meus).

${ }^{12}$ Rummert, Algebaile e Ventura (2013, p. 720) tratam de forma sintética a relação conflitiva entre a adaptação do Estado ao suporte central do processo de acumulação de capitais (Estado como secretário executivo dos interesses comuns às burguesias) e a demanda por elevação "[...] do nível de subsistência da força de trabalho, bem como de fazer frente às possibilidades de desestabilização advindas dos processos de correlações de forças, o que requer permanentes estratégias de controle social. É nesse cenário do capital-imperialismo que a educação é chamada à cena, de forma recorrente, como estratégia que visa a enfrentar o estado de indeterminação da contemporaneidade. No caso do Brasil, o capital-imperialismo assume forma e conteúdo particulares, marcados por ser o país, hoje, detentor de condições fundamentais para constituir um polo integrado subalternamente ao capital-imperialismo". Conceito esse adotado e difundido por Virginia Fontes (2010, p. 146-147), para indicar a preponderância do "[...] capital monetário, expressando a dominação da pura propriedade capitalista" e seu caráter expropriador que acarretam transformações estruturais no tocante às relações entre o conjunto dos interesses dos grandes empresários, "[...] o mundo do trabalho, a forma da organização política, a dinâmica da produção científica, a cultura; enfim, o conjunto da sociabilidade". 
Avançando naquilo que foi afirmado na oitava nota deste texto, compreende-se, com Gramsci, que não é somente por meio de uma organização específica da força que as classes economicamente dominantes mantêm seu domínio; lhes é necessário que uma direção moral, cultural e intelectual seja praticada. De forma meramente didática, é possível pensar que essa direção provê a configuração das forças materiais, entendidas mais como conteúdo, uma vez que essas não seriam historicamente concebíveis sem forma, e as ideologias seriam fantasias individuais sem as forças materiais.

A conformação a uma maneira de compreender o mundo lança mão do princípio da universalidade, movimento de ocultação no qual opera a ideologia, na medida que faz parecer natural, da ordem originária das coisas, aquilo que é socialmente produzido. Essa direção pode ser observada no conjugado de subsídios semânticos habitualmente recorrentes nos discursos de uma dada conjuntura. Para Fiorin (2000, p.19), “[...] esses elementos semânticos, assimilados por cada homem ao longo de sua educação, constituem a consciência e, por conseguinte, sua maneira de pensar o mundo", o que faz com que, historicamente, a normatização da educação das classes populares seja cada vez mais disputada pelas frações da burguesia.

Essa assimilação é concebida no interior de diferentes estratégias discursivas. Uma delas é a utilização dos mesmos elementos semânticos em enunciados de natureza ou finalidade muito distintas. Refiro-me aqui, no que compete à área das linguagens no Ensino Fundamental da BNCC, ao uso de um arsenal teórico crítico que recoloca ${ }^{13}$ em pauta uma concepção de linguagem ${ }^{14}$ ancorada no conceito de enunciado e seus derivados. Concepção essa que chega ao Brasil no último quadrante do século passado, que está pautada no pressuposto da discursividade sob a perspectiva do círculo de Bakhtin ${ }^{15}$ e que ganha notoriedade denunciando os limites de uma visão essencialmente formalista e estruturalista da linguagem. Para tanto, a centralidade do texto - e não do discurso - é reassumida como unidade do trabalho pela proposta, "[...] de forma a sempre relacionar os textos a seus contextos de produção e o desenvolvimento de habilidades ao uso significativo da linguagem em atividades de leitura, escuta e produção de textos em várias mídias e semioses" (BRASIL, 2017, p. 65).

Assim, a BNCC trabalha com a adesão a um conjunto de elementos teórico-críticos que historicamente foram ganhando espaço nas políticas curriculares e, antes disso, na comunidade científica, conforme extrato a seguir:

(EF15LP02) Estabelecer expectativas em relação ao texto que vai ler (pressuposições antecipadoras dos sentidos, da forma e da função social do texto), apoiando-se em seus conhecimentos prévios sobre as condições de producão e recepção desse texto, o gênero, o suporte e o universo temático, bem como sobre saliências textuais, recursos gráficos, imagens, dados da própria obra (índice, prefácio etc.), confirmando antecipações e inferências realizadas antes e

\footnotetext{
${ }^{13}$ Lembremos que essa concepção já esteve presente em documentos orientadores de políticas curriculares que precedem a BNCC, tais como os Parâmetros Curriculares Nacionais e a Diretrizes Curriculares Nacionais.

14 Três cortes epistemológicos mais nítidos nas concepções de linguagem que foram sendo adotadas pela história do pensamento ocidental são considerados. A primeira concepção seria a linguagem como expressão do pensamento, na qual o fenômeno linguístico foi abreviado "[...] a um ato monológico, individual, que não é afetado pelo outro nem pelas circunstâncias que constituem a situação social em que a enunciação acontece” (TRAVAGLIA, 1997, p. 21). A segunda, inventariada pelo estruturalismo saussuriano, entende a linguagem como instrumento da comunicação. Concepção que "[...] levou ao estudo da língua enquanto código virtual, isolado de sua utilização [...] e fez com que a Lingüística não considerasse os interlocutores e a situação de uso como determinantes das unidades e regras que constituem a língua, isto é, afastou o indivíduo falante do processo de produção, do que é social e histórico na língua. Essa é uma visão monológica e imanente da língua, que a estuda segundo uma perspectiva formalista - que limita esse estudo ao funcionamento interno da língua - e que separa o homem no seu contexto social" (TRAVAGLIA, 1997, p. 21). E a terceira concepção de linguagem, adotada de forma reducionista pela BNCC, seria aquela que a compreende como lugar de ação, interação e prática social.

${ }^{15}$ Fundamentado nos estudos da teoria marxiana, principalmente na oposição entre o materialismo de Feuerbach e o idealismo hegeliano, o Círculo de Bakhtin pôs em dúvida as grandes correntes teóricas da linguística existentes na segunda metade do século passado, que restringiam a linguagem ou a um subjetivismo idealista, tomando-a como enunciação monológica isolada; ou a um objetivismo abstrato, que a compreendida como o já referido sistema abstrato de formas normativas (BAKHTIN, 1997). A partir dessa oposição, a língua em uso passa a ser objeto principal de estudo, e a linguagem é compreendida no "[...] sentido de conjunto dos contextos possíveis de uso de cada forma particular" (BAKHTIN, 1997, p. 95).
} 
durante a leitura de textos, checando a adequação das hipóteses realizadas (BRASIL, 2017, p. 95, grifos meus).

Algumas páginas à frente, como mais uma habilidade a ser alcançada, o documento indica o que segue: "(EF35LP22) Perceber diálogos em textos narrativos, observando o efeito de sentido de verbos de enunciação e, se for o caso, o uso de variedades linguísticas no discurso direto" (BRASIL, 2017, p. 133). Guardemos essa estrutura sintática e a escolha de elementos que compõem sua unidade de sentido.

Considerando ainda o pressuposto de que os documentos têm função didática (BENJAMIN, 2013), como um segundo movimento interpretativo do mesmo, foi necessário analisar, de maneira mais cautelosa, como esses elementos semânticos de estrutura mais profunda e historicidade demarcada se materializam no discurso, pois cada um deles não tem apenas uma semântica característica, mas se concretizam em uma estrutura sintática própria, afinada com a forma como o documento funciona socialmente. Neste estudo, proceder dessa forma nos permite compreender, com maior nitidez, a determinação ideológica a ele subjacente, não somente pela identificação dos principais envolvidos, mas pela exposição dos modos como esse conteúdo vem sendo normatizado. Nas palavras de Fiorin (2000, p. 21), examinar as coerções ideológicas e a tentativa de produção de consenso somente "[...] com os elementos da estrutura profunda pode [...] falsear a análise. É no nível superficial, isto é, na concretização dos elementos semânticos da estrutura profunda que se revelam, com plenitude, as determinações ideológicas".

Essas construções funcionam como racionalizações que elucidam e justificam a realidade imediata, além de essa realidade retroalimentar aquelas. Se vigora de maneira tão enraizada o fato de que os objetos do conhecimento não têm sentido senão quando estão a serviço de uma ação, mesmo que ela seja a mais trivial possível, além de isso ser sustentado por uma racionalidade que prima pelo utilitarismo, pela racionalidade instrumental (ADORNO; HORKHEIMER, 1985), é no nível fenomênico da realidade que as mesmas são constituídas e perpetuadas em uma dada formação social. Nesse sentido que "[...] aí tem importância capital a estrutura sintática da definição" (FIORIN, 2000, p. 40), que se repercute ao longo de todo documento e que "[...] modifica o conteúdo no plano de sua expressão" (p. 38).

$\mathrm{Na}$ estrutura sintática em que as habilidades são apresentadas, tem-se a seguinte fórmula convencionada: verbo + complemento + modificador, a depender do sintagma que constituirá a unidade significativa. A título de exemplo, observemos: "(EF02LP27) Reescrever [(verbo)] textos narrativos literários [(complemento)] lidos pelo professor [(modificador)]" (BRASIL, 2017, p. 109). Considerando a hierarquização de elementos linguísticos que compõem a sentença, o enfoque da referida estrutura incide sobre aquilo que o verbo demanda, nesse caso, reescrever, de modo que a experiência que advém na relação estabelecida com textos narrativos literários resta, pela própria maneira como o documento é redigido, secundarizada. Notemos aqui que o complemento é, de maneira geral, o objeto do conhecimento mobilizado na habilidade; o verbo constitui o processo cognitivo da habilidade em si requerida e o modificador apresenta um uso mais abrangente, podendo fazer alusão às formas como o objeto é tratado, ao contexto, às ferramentas que serão utilizadas para facilitação de sua apropriação, à "[...] explicitação da situação ou condição em que a habilidade deve ser desenvolvida" (BRASIL, 2017, p. 30), dentre outras recorrências similares que operem na modificação do verbo ou do complemento em questão. Nessas condições, reafirma-se que aquilo que está se tornando suplementar no referido exemplo é o texto - nessa habilidade, o literário -, elemento que a proposta do documento afirma assumir como sua centralidade "[...] como unidade de trabalho" (BRASIL, 2017, p. 65). E resta, contraditoriamente, o indicativo de que o fundamental não é tão fundamental assim.

Observada essa estrutura em que são descritas as habilidades a serem desenvolvidas e a função essencial que o verbo desempenha nelas, passa a ser foco de investigação novamente a dimensão semântica, no que compete ao sentido que esses verbos vêm dando às sentenças e, consequentemente, ao trato com os objetos do conhecimento. Dessa forma, é agregada à análise mais uma dimensão, trabalhando em duas direções, pois tanto o local privilegiado sintaticamente que ocupam esses verbos pode modificar o valor conferido aos demais elementos semânticos (objetos do conhecimento) usados nas sentenças, quanto a própria escolha dos verbos que conferem sentido a essas habilidades. Essa 
apreciação é realizada primeiro na área das linguagens do Ensino Fundamental e depois, ainda que não componha objetivo deste trabalho, estende-se, muito brevemente, às demais áreas da mesma etapa da Educação Básica.

"(EF15LP03) Localizar informações explícitas em textos. (EF15LP04) Identificar o efeito de sentido produzido pelo uso de recursos expressivos gráfico-visuais em textos multissemióticos" (BRASIL, 2017, p.93, grifos meus) são exemplos característicos de habilidades a serem desenvolvidas no ensino da Língua Portuguesa do $1^{\circ}$ ao $5^{\circ}$ ano do Ensino Fundamental. Os verbos grifados, utilizados para denotar o processo cognitivo da habilidade em si requerida, apresentam carga semântico bastante recursiva no documento em questão.

Os gráficos exibidos abaixo expõem, respectivamente, o levantamento feito dos verbos mais recorrentes que denotam habilidades da L.P para o E.F e para essa mesma etapa da Educação Básica considerando todas as áreas do conhecimento.

Gráfico 1: Verbos mais recorrentes nas habilidades da L.P. para o E.F.

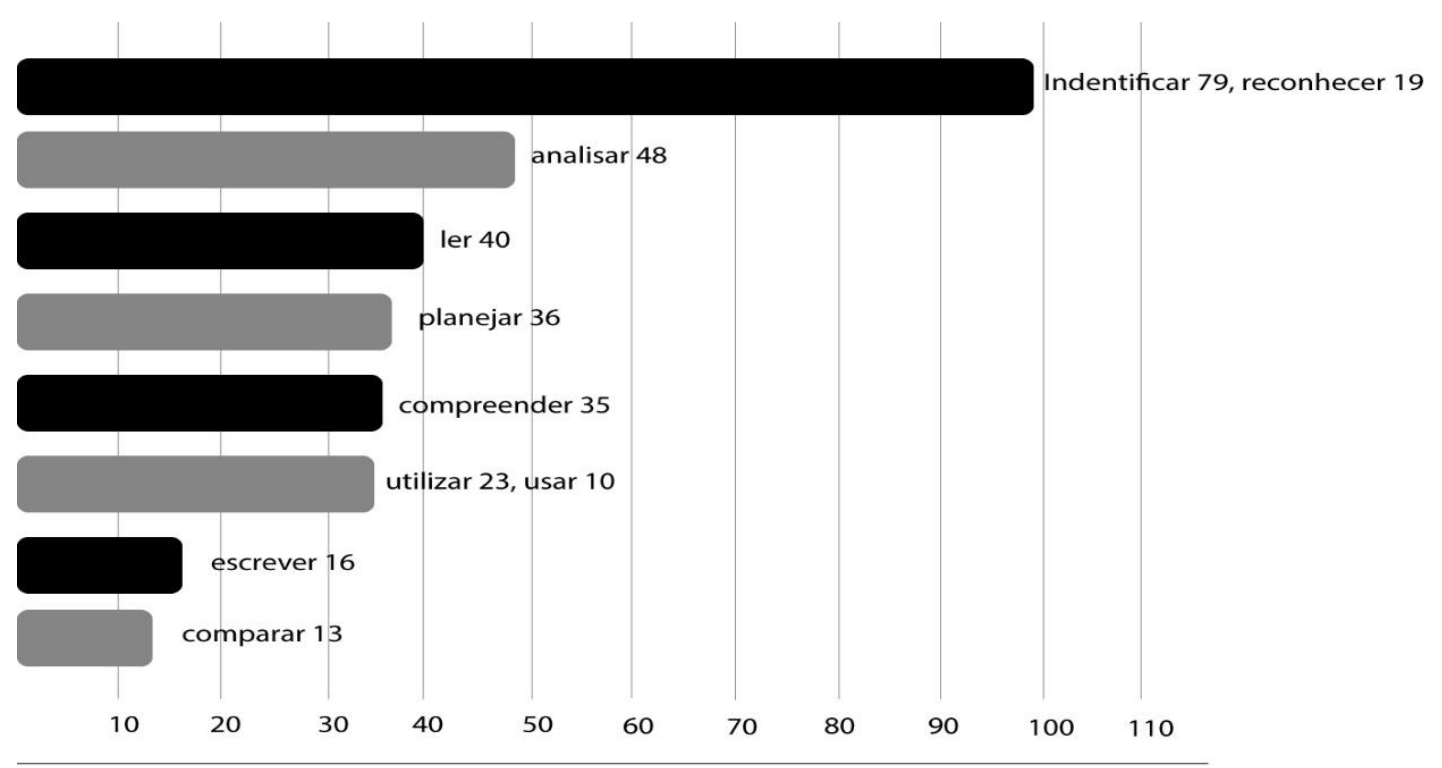

Fonte: Brasil, 2017. Elaborado por Elvis Riboli. 
Gráfico 2: Verbos mais recorrentes nas habilidades para o E.F.

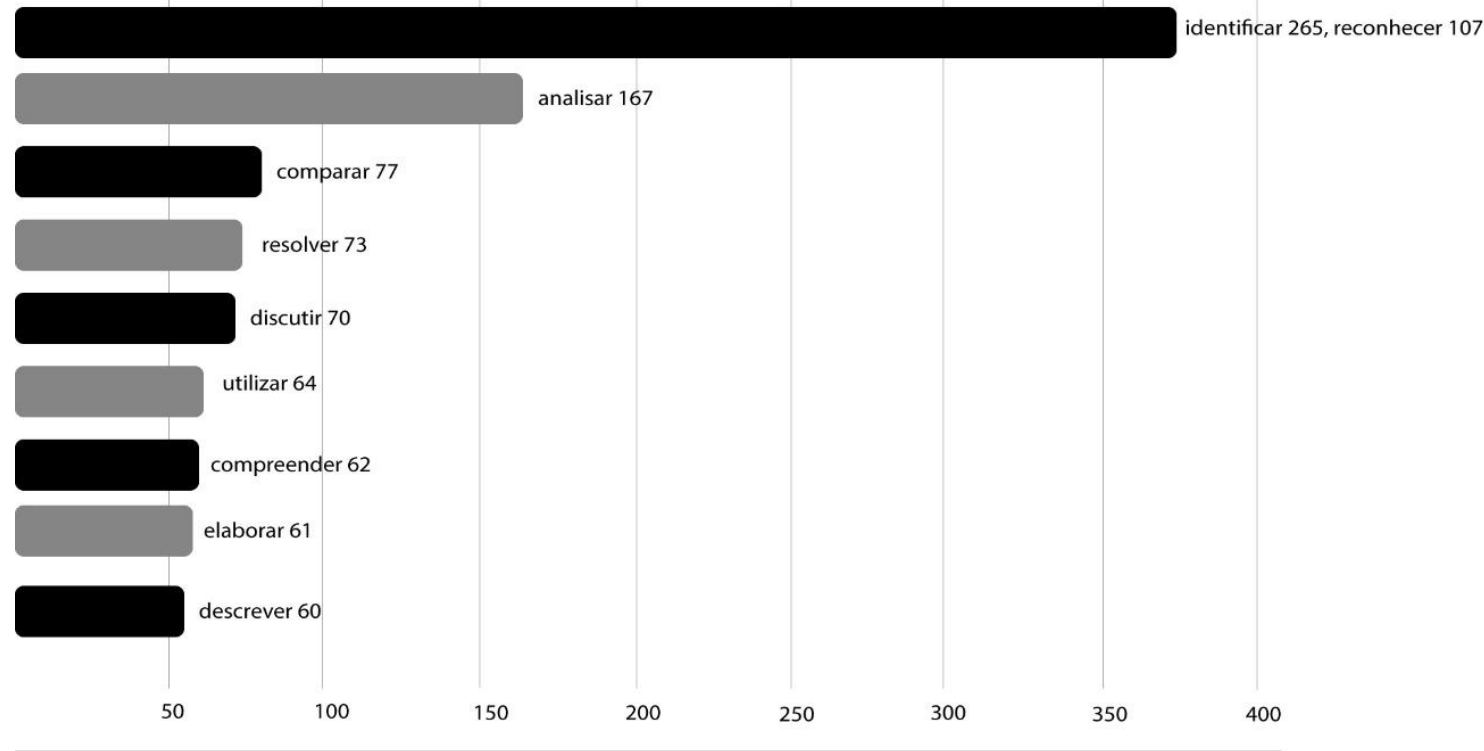

Fonte: Brasil, 2017. Elaborado por Elvis Riboli.

Em uma perspectiva mais panorâmica, agora sem deter-me a uma das áreas do conhecimento minuciosamente, permanece notória a centralidade e a recorrência que ganham aqueles cuja carga semântica denotam menor envolvimento crítico e até mesmo cognitivo por parte dos estudantes. Verbos como contrapor, argumentar, criticar, entender quase não aparecem, até porque, mesmo em uma normativa pautada pela ideologia das competências, poderiam ser o princípio do processo de desmentir o seu em-si ausente de historicidade. Em contrapartida, verbos que trazem sentidos bastante restritos e colocam o aluno em uma posição ordeira mediante o conhecimento são muito recorrentes. A exemplo disso, logram destaque utilizar e descrever, que aparecem mais de 100 vezes no documento.

É pertinente apontar, finalmente, o verbo mais utilizado na Base, qual seja: identificar. Usado no sentido de distinguir, ter a capacidade de reconbecer ou meramente classificar, o verbo em questão apresenta uma recorrência de 567 vezes na BNCC, mais uma evidência não somente de seu caráter instrumental e do consequente empobrecimento da atividade cognitiva que a política em questão provoca, mas da secundarização que os conteúdos histórica e cientificamente produzidos e sistematizados sofrem. Nesse sentido, notemos "[...] que essa supremacia do caráter instrumental dos discursos educacionais não implica o desaparecimento de disciplinas e saberes tidos como integrantes de uma concepção humanista de formação". E isso ocorre até mesmo com "[...] a literatura, as artes ou a filosofia. Significa, antes, que mesmo esses saberes e disciplinas passam a ter outro papel: o de coadjuvantes na supremacia do instrumentalismo vinculado ao mercado e à sociedade de consumidores" (CARVALHO, 2017, p. 30).

Análises empreendidas em outros componentes curriculares que tratam da mesma área do conhecimento demonstram fenômeno semelhante ao argumento que vem sendo construído neste escrito. Estudos realizados por Pessoa (2018, p. 179) apontaram que o consenso central da Educação Física na constituição da BNCC pode ser determinado pela inclusão no documento "[...] da educação física tratando as práticas corporais como produções humanas, produções de cultura [...]" conforme aludido por um de seus interrogados. A referida pesquisa pontua que,

[...] ao olhar demasiadamente para a especificidade da área, o CBCE e os especialistas acabaram por desconsiderar os efeitos nocivos à democracia que a aprovação desta BNCC tende a produzir, bem como ignoraram a BNCC como aprimoramento do projeto de educação hegemonizado por setores do empresariado brasileiro. Ao aceitar a incorporação de arcabouço teórico crítico ao documento acabaram enfraquecendo a luta por um projeto de educação Educação em Revista|Belo Horizonte|v.37|e228059|2021 
autônomo da classe trabalhadora. Portanto, o corporativismo foi a marca da Educação Física na BNCC. [...] Tal posicionamento implica o enfraquecimento da luta dos professores e entidades por um projeto de educação adequado e digno para a classe trabalhadora, com autonomia real e, principalmente, independente de conciliação entre as classes antagônicas (PESSOA, 2018, p. 176). ${ }^{16}$

No que concerne ao Ensino da Arte, outro componente curricular que compõe a área das linguagens, Iavelberg (2018, p.76) manifesta que a BNCC “[...] revela uma indefinição no que se refere aos conteúdos do ensino”. Da mesma forma, a indicação de definições e balizas teóricas são inexistentes, como nos demais componentes da área. Isto é, os aspectos essenciais da área que foram constituindo o “[...] objeto de estudo no fazer artístico pessoal (a concretizar-se em produtos artísticos) e nas análises sobre artistas, obras de arte, modos de comunicação, públicos e suas histórias" (FERRAZ; FUSARI, 2009, p. 146), tornam-se quase obsoletos no documento. A autora verifica que "[...] os conteúdos redigidos nos PCN tornaram-se habilidades na BNCC, demarcando, nessa passagem, tanto continuidades como descontinuidades" (2018, p. 78).

Logo, aquele conjunto de elementos teórico-críticos defendidos na contemporaneidade é colocado a serviço daqueles verbos recém comentados e em uma estrutura de proposta que, de maneira global, responde a um saber como e torna acessório um saber que ou, mais ainda, um saber por quê. Somandose a tal esvaziamento, essa estratégia tende a tornar ainda mais nebulosa a proposta de maneira global, além de afastar os professores do embate por um programa de educação que traga em seu cerne o acesso ao conhecimento cientificamente organizado de maneira crítica, como necessidade primeira da escola que atende os filhos da classe trabalhadora. Isto é, favorece que muitos professores não manifestem resistência à política curricular em questão por se sentirem representados por uma proposta que alocaria suas convicções teórico-práticas, ainda que de maneira bastante pueril, como é discutido na próxima seção.

\section{SEMIFORMAÇÃO SOCIALIZADA COMO HORIZONTE DA BNCC}

A crítica fundamental exposta por Theodor W. Adorno em Teoria da Semicultura consiste em expor a conversão da formação cultural em uma semiformação socializada, que não ocorre antes da formação cultural, mas a substitui como fato completo e acabado. Isto é, um dos objetivos de Adorno é mostrar uma traiçoeira realização que vem sendo tomada como formação, em virtude de uma tentativa de apreensão carente de conjecturas, sem experiência efetiva com o que se deseja e necessita conhecer, que favorece uma passagem aligeirada pela empiria por parte do sujeito, e que, por isso, não poderia ser tomada como formação. "O entendido e experimentado medianamente - semi-entendido e semiexperimentado - não constitui o grau elementar da formação, e sim seu inimigo mortal” (ADORNO, 1996, p. 403), uma vez que desonera, tanto quanto possível, a experiência sensível do sujeito. Com efeito, tornam-se "[...] elementos que penetram na consciência sem fundir-se em sua continuidade, se transformam [...] tendencialmente, em superstições, até mesmo quando as criticam" (1996, p. 403, grifo meu). A semiformação, uma das expressões do objeto em análise, vem favorecendo que a BNCC atenda às diferentes requisições individuais dos sujeitos envolvidos. Isto é, tanto daqueles que objetivam a formação voltada para o mercado de trabalho; quanto daqueles que buscam um - ainda que raso - engajamento nas perspectivas críticas contemporâneas, seja nas linguagens, na matemática, nas ciências biológicas, nas ciências humanas.

\footnotetext{
${ }^{16}$ Ainda que não componha fenômeno explicitamente tratado neste artigo, o autor observa inclusive um "[...] ocultamento das [...] tensões e disputas no interior da área, mediante o estabelecimento de acordos pontuais da Educação Física na construção da BNCC, [que] trazem implicações políticas no sentido de dar aparência de consenso ante as diferenças de compreensão do objeto de estudo e ensino, bem como do caráter da Educação Física na escola", de modo que a política em questão esteja apaziguando alguns fundamentais conflitos que permanecem "[...] latentes no interior da área" (PESSOA, 2018, p. 177).
} 
Bem como denunciou Adorno a respeito de tal conceito, na Base, a sua caricatura é extremamente contraditória, pois, ao oferecer a cultura, a nega. As habilidades e competências, quando relacionadas àquela perspectiva crítica dos conteúdos, “[...] compõem um substitutivo da experiência, falso e aparentemente próximo, em lugar da experiência destruída" (ADORNO, 1996, p. 407). Quando a lei da causalidade e da classificação abstrata substituem a experiência sensível, a realidade como critério de verdade e a perspectiva histórica e dialética, “[...] o semiculto transforma, como que por encanto, tudo que é mediato em imediato, o que inclui até o que mais distante” está (1996, p. 407). Isso o impede cada vez mais de perceber que as relações sociais que na superfície discursiva manifestam-se como relações individuais, apagando as determinações sociais de cada um, são, em essência, relações conflitivas entre as diferentes classes sociais.

Análogo ao que foi afirmado sobre a espoliação do trabalho humano nas palavras introdutórias, as semelhanças de interesse entre as diferentes classes sociais permanecem tão-somente no plano fenomênico, que aqui pode ser compreendido como superfície discursiva do documento e também a sua condução diretiva nos locais de ensino. Isto é, essa hipotética equivalência de interesses entre as frações da burguesia e os docentes que venham a se sentir representados pela política em questão acontece, majoritariamente, no que Adorno chamou de mercado das trocas, espaço da socialização imediata, que enleia contrários e, ao solidariamente oferecer o conhecimento organizado, no nível fenomênico, recusa-o em sua experiência mais substantiva.

Nesse sentido, da mesma forma que não é sempre a mesma coisa falar em liberdade, criatividade, interação, termos costumeiramente ressemantizados no discurso educacional comodificado (FAIRCLOUGH, 2001), também não o é falar em "[...] condições de produção dos textos" (BRASIL, 2017, p. 75 e p. 77) e de subsídios linguísticos outros que carregam uma aura positiva em sua cristalização (MAINGUENEAU, 1997), que são correntemente apropriados pelos documentos que orientam e normatizam as políticas educacionais. Alteram-se os falantes, suportes, formações discursivas, entretanto, a construção dos discursos permanece compondo um investimento em "[...] estruturas sintáticas abstratas, temas e figuras, que materializam valores, carências, desejos, explicações, justificativas e racionalizações existentes" (FIORIN, 2000, p. 43). Isso subjaz à relação traiçoeira estabelecida entre indivíduo e discurso, pois a não ciência do processo de dissimulação do que lhe é alheio torna ainda mais distante a consciência de sua formação social (FAIRCLOUGH, 2001) e, principalmente, dos seus interesses primeiros como classe social ${ }^{17}$.

Essa dissimulação ocorre porque um plano de manifestação individual é que veicula um plano de conteúdo social. Assim, o discurso simula ser individual para ocultar o que é social. Ao realizar essa simulação e essa dissimulação, a linguagem serve de apoio para as teses da individualidade de cada ser humano e da liberdade abstrata de pensamento e de expressão. O homem coagido, determinado, aparece como criatura absolutamente livre de todas as coerções sociais (FIORIN, 2000, p. 42).

A apreciação do documento, a partir da perspectiva teórico-metodológica adotada, à luz do conceito de semiformação, torna evidente a tentativa de uso de instrumentos arbitrários que permitam ao indivíduo que se apodere não da realidade percebida, mas dos seus aspectos fenomênicos, de forma bastante carente de uma relação substantiva com o conhecimento científico, filosófico e artístico socialmente organizados e fundamentados pelas experiências individuais e coletivas dos sujeitos. Esses conhecimentos objetivos são desconjuntados da luta histórica pela liberdade dos homens e os descomunais contrastes sociais permanecem atenuados, obscurecidos pela rotineira aparição de desconexos eventos conjunturais, pois o todo desses contrastes - a unidade desses acontecimentos - não chega a ser levado às suas últimas consequências (LUKÁCS, 2010). Além disso, ainda que não seja aspecto central de análise desta discussão, é importante notar que é sob o uso artificioso e

\footnotetext{
${ }^{17}$ Fiorin denomina o enunciador como suporte do discurso, e, por conseguinte, “[...] os agentes discursivos são as classes e as frações de classes. Tornamos a lembrar que, embora haja diferentes formações discursivas numa formação social, a formação discursiva dominante é a da classe dominante. O 'árbitro' da discursivização não é o indivíduo, mas as classes sociais. O indivíduo não pensa e não fala o que quer, mas o que a realidade impõe que ele pense e fale” (2000, p. 43).

Educação em Revista|Belo Horizonte|v.37|e228059|2021
} 
descomprometido (política, social e esteticamente) do conceito de formação integral (BRASIL, 2017) que esses instrumentos arbitrários também se manifestam e logram legitimidade na proposta.

Dessa forma, é importante que se reconheça que, se o que pode fazer com que os licenciados das diferentes áreas do conhecimento assumam esse projeto encabeçado pelas frações da burguesia, sem problematizar seus determinantes históricos, aspectos constitutivos e interesses políticos substanciais, não é difícil é perceber que essa adesão será prosaica, frágil e promíscua. Isso porque o que seria uma das motivações de sua anuência - aderência aparente aos conceitos advindos de uma perspectiva crítica e engajada socialmente - está a serviço de um precário envolvimento com aquilo que se quer e se necessita efetivamente conhecer. O mesmo vale para os argumentos que sugerem que consideremos com parcimônia as aproximações e os distanciamentos da Base, pois esses concernem àquilo que o andar de baixo mais necessita para a mudança de sua condição de subalternidade; enquanto aquelas constituem aspectos, em síntese, funcionalistas e instrumentais, para os quais não precisaríamos de uma base. Assim, nada de substantivo há nessas hipotéticas oportunidades ofertadas pela BNCC que já não estivesse ao alcance dos (ou transcendido pelos) currículos das escolas, das propostas curriculares estaduais e municipais.

A política em questão opera de modo satisfatório na inserção das ideias de regeneração aparente da cultura democrática, da cultura cívica, de estimulo não à cultura radicalmente participativa, mas à socialização da pseudoparticipação, como mais uma força no progresso dos interesses das frações política e economicamente dominantes, deixando evidente que a "[...] ação sobre as circunstâncias [...] é inseparável de uma ação sobre as consciências" (VÁZQUEZ, 2011, p. 152). Em ouras palavras, colabora na edificação da subjetividade coletiva do senso comum, fundamentada em relações flexíveis que buscam, de forma bastante utilitária, atrelar avanço da ciência e mercado de trabalho, relacionados em objetivos afins. Essa função subalterna de manutenção "[...] da hegemonia social e do governo político" (GRAMSCI, 2016, p. 22) exercida por professores e intelectuais de diferentes áreas do conhecimento e que os coloca, mesmo que indiretamente, na condição de representantes da classe dirigente e dominante, na maioria esmagadora das vezes, não ocorre de modo intencional. Entretanto, os insere no movimento, ainda que de forma menos ostensiva, daquilo que Giddens (2005), citado por Motta (2009), indicou como reestabelecimento da autoridade via individualismo democrático, que exige das classes dominantes uma adesão à solidariedade social limitada ao que demanda a economia, inclusive no terreno dos currículos oficiais, no qual o lucro se aufere a longo prazo.

\section{CONSIDERAÇÕES FINAIS}

"Assim não era possivel atingir toda a verdade, porque cada metade trazia o perfil da meia verdade" (ANDRADE, 1987, p. 41).

Como foi dito nas palavras introdutórias deste escrito, ele deve ser lido como mais um elemento na compreensão das leis gerais de funcionamento do todo. Busquei trazer para o centro da discussão estabelecida que, seja pela sua intencionalidade, seja pelos interesses em disputa, pela análise dos principais envolvidos (como vem sendo bastante difundido pela comunidade científica) e também pelo modo como a referida política se expressa na superfície discursiva, o uso do arsenal crítico contemporâneo das áreas do conhecimento é convertido em uma semiformação socializada. Essa pode facilmente ser acolhida e defendida pelas convicções teórico-práticas dos professores nas diferentes áreas, o que provavelmente não aconteça quando a política é compreendida como unidade sintética de múltiplas determinações históricas, econômicas e sociais.

Isso ocorre uma vez que os intelectuais orgânicos das associações de monopólios empresariais, além de transitarem com maestria na mídia de massa, fazem um esforço discursivo para satisfazer aqueles profissionais da educação que desconhecem tanto essas esferas de influência quanto a referida política de modo global. Esse jogo faz prosperar uma adoção a mais consensual possível das suas propostas, justamente porque a superfície discursiva expressa uma representação aparente das convicções teórico-práticas historicamente constituídas e legitimamente defendidas pelos professores no interior de suas áreas de atuação. Infelizmente, no âmago da ideologia das competências, o referido arsenal teórico- 
crítico se torna para os alunos quase que superstição, uma vez que os conteúdos do conhecimento são secundarizados nesse processo. Isto é, são subjugados às habilidades, às competências e a atividades que demandam pouco envolvimento crítico, político e até mesmo cognitivo dos estudantes. Essa circunstância provoca a sociabilidade mais harmônica possível não somente das disfunções conjunturais, mas perpetua uma forma incauta de nos relacionarmos com o conhecimento e com as pessoas. Suportada pelas evidências ora abordadas, essa é mais uma maneira como o conteúdo político, ao passar pelo crivo dos especialistas, reveste-se de soluções meramente técnicas, avolumando sua aura de inevitabilidade.

Dessa forma, ainda que o documento normativo traga para o centro da proposta um perfume progressista, com uma frívola perspectiva crítica de cada uma dessas áreas, o princípio dessa crítica é cristalizado por uma ação inexpressiva, esvaziado de sentido e facilmente socializado como mais um clichê no mercado das trocas. Isso cai como uma luva para a mudança de opiniões, entretanto, agravamse os entraves para a transformação das relações materiais que determinam nossa existência.

\section{REFERÊNCIAS}

ADORNO, T. W. Teoria da Semicultura. In: Educação e Sociedade. Ano XVII, nº.56, pp. 388-411, 1996.

ADORNO, T. W.; HORKHEIMER, M. Dialética do Esclarecimento. Rio de Janeiro: Zahar, 1985.

AGUIAR, M. A. S.; DOURADO, L. (Org.). A BNCC na contramão do PNE 2014-2024: avaliação e perspectivas. Recife: ANPAE, 2018.

ANDRADE, C. D. Verdade. In: ANDRADE, C. D. Corpo. 10ª ed. Rio de Janeiro: Record, 1987, pp. 41-42.

ANTUNES, R. Desenhando a nova morfologia do trabalho no Brasil. Revista Estudos Avançados. v. 28, n. 81, pp. 39-53, 2014.

ANTUNES, R. O privilégio da servidão: o novo proletariado de serviços na era digital. São Paulo: Boitempo, 2018.

BAKHTIN, M. Marxismo e filosofia da linguagem. Hucitec: São Paulo, 1997.

BENJAMIN, W. Rua de mão única: infância berlinense: 1900. Belo Horizonte: Autêntica Editora, 2013.

BENJAMIN, W. O Surrealismo. O último instantâneo da inteligência europeia. In: BENJAMIN, W. Obras escolhidas: Magia e Técnica, Arte e Política. São Paulo: brasiliense, 1994.

BRASIL. Constituição da República Federativa do Brasil. Brasília: Senado Federal, 1988.

BRASIL. Emenda Constitucional nº. 59, de 11 de novembro de 2009.

BRASIL. Lei $\mathbf{n}^{\mathbf{0}} \mathbf{1 3 . 0 0 5}$ de 25 de junho de 2014. Aprova o Plano Nacional de Educação e dá outras providências (2014-2024). Brasília: Câmara dos Deputados, 2014.

BRASIL. Ministério da Educação. Base Nacional Comum Curricular. Brasília: MEC, 2017.

BRASIL. MEC. CNE. Diretrizes Curriculares Nacionais e Base Nacional Comum para a Formação Inicial e Continuada de Professores da Educação Básica, 2019.

CARVALHO, J. S. F. Educação uma herança sem testamento: diálogos com o pensamento de Hannah Arendt. São Paulo: Perspectiva, 2017. 
CHAVES, P. M.; EVANGELISTA, O. Servidão benevolente até a morte? Contrapoder. Disponível em: $<$ https://contrapoder.net/colunas/servidao-benevolente-ate-a-morte/>. Acesso em: 24 nov. 2020.

CHAVES, P. M.; FLORES, R.; EVANGELISTA, O. Ensino híbrido cai sobre o professorado.

Contrapoder. Disponível em: <https://contrapoder.net/colunas/ensino-hibrido-cai-sobre-Oprofessorado/> Acesso em: 24 nov. 2020.

FAIRCLOUGH, N. Discurso e mudança social. Brasília: Universidade de Brasília, 2001.

FAIRCLOUGH, N. Análise Crítica do Discurso como Método em Pesquisa Social Científica. Linha d'Água, n. 25 (2), 2012. pp. 307-329

FERRAZ, H. C. de T.; FUSARI, M. F. R. Metodologia do ensino da arte. São Paulo: Cortez, 2009.

FONTES, V. O Brasil e o capital-imperialismo: teoria e história. Rio de Janeiro: EPSJV/Editora UFRJ, 2010.

FONTES, V. Capitalismo, crises e conjuntura. In: Serviço Social e Sociedade, São Paulo, n. 130, pp. 409-425, 2017.

FREITAS, L. C. de. Dia D da BNCC: 12 razões para não ser coadjuvante. 2018. Disponível em: $<$ https:/ / avaliacaoeducacional.com/2018/03/05/dia-d-da-bncc-12-razoes-para-nao-sercoadjuvante/>. Acesso em: 25 abr. 2019.

GRAMSCI, A. Cadernos do Cárcere: Maquiavel, a política e o Estado moderno. V. 3. Rio de Janeiro: Civilização Brasileira, 2016.

IAVELBERG, R. A Base Nacional Curricular Comum e a formação dos professores de arte. Horizontes, v. 36, n. 1, pp. 74-84, jan./abr. 2018.

LUKÁCS, G. Marxismo e teoria da literatura. São Paulo: Expressão Popular, 2010.

PEREIRA, J. N.; CHAVES, P. M.; EVANGELISTA, O.; SOUZA, A. G. "Pelo futuro agora": De frente para a tragédia na escola pública. Contrapoder. Disponível em: https://contrapoder.net/colunas/pelofuturo-agora-de-frente-para-a-tragedia-na-escola-publica/. Acesso em: 24 nov. 2020.

PERONI, V. M. V.; CAETANO, M. R. O público e o privado na educação Projetos em disputa? In: Revista Retratos da Escola, Brasília, v. 9, n. 17, pp. 337-352, jul./dez. 2015.

PESSOA, F. M. A Educação Física na construção da Base Nacional Comum Curricular: consensos, disputas e implicações político-pedagógicas. 2018. 202 f. Dissertação. Universidade Federal de Santa Catarina, Florianópolis, 2018.

MAINGUENEAU, D. Novas Tendências em Análise do Discurso. $3^{\mathrm{a}}$. ed. Campinas: Editora da Universidade Estadual, 1997.

MOTTA, V. C. Ideologias do capital humano e do capital social: da integração à inserção e ao conformismo. Trabalho, Educação e Saúde, Rio de Janeiro, v.6, n.3, pp.549-572, 2008.

RUMMERT, S. M; ALGEBAILE, E.; VENTURA, J. Educação da classe trabalhadora brasileira: expressão do desenvolvimento desigual e combinado. Revista Brasileira de Educação, Rio de Janeiro, v. 18, n. 54, pp. 717-738, Set. 2013.

TARLAU, R.; MOELLER, K. O consenso por filantropia: Como uma fundação privada estabeleceu a BNCC no Brasil. Currículo sem Fronteiras, v. 20, n. 2, pp. 553-603, maio/ago. 2020.

TRAVAGLIA, L. C. Gramática e Interação: uma proposta para o ensino de gramática no $1^{\circ}$ e $2^{\circ}$ graus. São Paulo: Cortez, 1997.

VÁZQUEZ, A. S. Filosofia da Práxis. São Paulo: Expressão Popular, 2011. 
WILLIAMS, R. Marxismo e literatura. Rio de Janeiro: Jorge Zahar, 1979.

Submetido: $05 / 09 / 2019$

Aprovado: $23 / 11 / 2020$ 